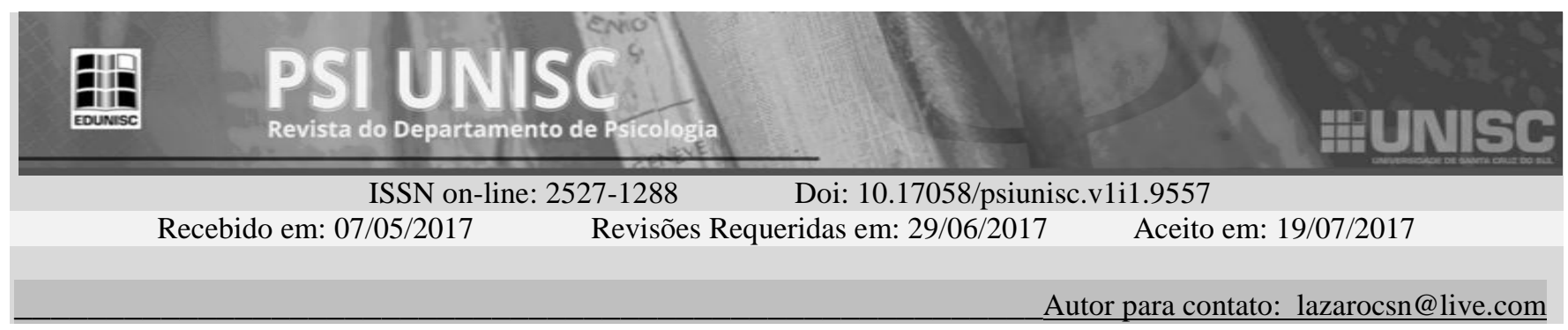

\title{
Reflexões acerca da formação em Gestalt-terapia no Brasil ${ }^{1}$
}

Reflexiones acerca de la formación en Gestalt-terapia en Brasil

Reflections about Gestalt Therapy training in Brazil

Lázaro Castro Silva Nascimento

Universidade de Brasília - Distrito Federal - Brasil

Jorge Ponciano Ribeiro

Universidade de Brasília - Distrito Federal - Brasil

\section{RESUMO}

O primeiro instituto de Gestalt-terapia foi fundado em 1952 nos Estados Unidos. Com o passar dos anos, a Gestalt-terapia se difundiu em diversos países no mundo incluindo o Brasil. A sua larga difusão trouxe também formas variadas para a formação de Gestalt-terapeutas. Este trabalho é uma revisão narrativa de literatura acerca das formações em Gestalt-terapia. Buscamos compreender esta diversidade na literatura gestalt-terapêutica especificamente no solo brasileiro. Inicialmente a Gestalt-terapia ganhou bastante visibilidade nos EUA a partir dos workshops ofertados por Fritz Perls. Contudo, sua consistência teórica e sua difusão sistemática foram realizadas a partir da criação de institutos e de associações. Concluímos que a formação em Gestalt-terapia no Brasil parece acontecer por, pelo menos, duas vias: 1) cursos livres/especializações; 2) a partir de estudo e supervisão clínica com Gestalt-terapeuta mais experiente; Contudo, é comum encontrar "Gestalt-terapeutas autointituladas/os" que tiveram contato com a Gestaltterapia apenas em cursos de graduação.

Palavras-chave: Formação de gestalt-terapeutas. Gestalt-terapia. Literatura gestáltica.

\section{RESUMEN}

El primer instituto de la terapia Gestalt fue fundado en 1952 en los Estados Unidos. Con los años, la terapia Gestalt se ha extendido en varios países del mundo, incluyendo Brasil. Su amplia difusión también trajo varias formas para la formación de terapeutas de la Gestalt. Este trabajo es una revisión

\footnotetext{
${ }^{1}$ Trabalho construído a partir da pesquisa de doutorado do primeiro autor com orientação do segundo autor. Os dados aqui apresentados compõem parcialmente a pesquisa ainda em andamento (PPG-PsiCC/UnB, 2015-2019).
}

PSI UNISC, Santa Cruz do Sul, Vol. 1, n. 1, jul./dez. 2017, p.<142-153>. 
narrativa de la literatura acerca de la formación en la terapia Gestalt. Buscamos entender esta en suelo brasileño. Inicialmente la terapia Gestalt ganó mucha visibilidad en los EE.UU. con los talleres ofrecidos por Fritz Perls. Sin embargo, su consistencia teórica y difusión sistemática se hicieron desde con la creación de institutos y asociaciones. Resulta que la formación en Terapia Gestalt en Brasil parece suceder por lo menos de dos maneras: 1) cursos / especialización; 2) a partir del estudio y de supervisión clínica con alguna/o experimentada/o terapeuta Gestalt; Sin embargo, es muy común encontrar "Gestaltterapeutas autointituladas/os" que tuvieron contacto con la Terapia Gestalt sólo en cursos de graduación.

Palabras clave: Formación de gestalt-terapeutas. Gestalt-terapia. Literatura gestáltica.

\section{ABSTRACT}

The first institute of Gestalt therapy was founded in 1952 in the United States. Over the years, Gestalt therapy was spread in various countries in the world including Brazil. This wide diffusion also brought various forms for the training of Gestalt therapists. This research is a narrative review of the literature about Gestalt therapy training. We aim to understand this diversity in specifically on Brazilian soil. Initially Gestalt therapy gained much visibility in the US with workshops offered by Fritz Perls. However, its theoretical consistency and systematic dissemination were achieved with the creation of institutes and associations. Conclusion shows that Gestalt therapy in Brazil seems to happen for at least two ways: 1) Courses/specializations; 2) Taking classes and clinical supervision with an experienced Gestalt therapist; 3) contact with Gestalt therapy in undergraduate courses. However, it's common to find "self-nominated Gestalt therapists" who have had contact with Gestalt therapy only in undergraduate courses.

Keywords: Gestalt therapy training. Gestalt therapy. Gestaltic literature.

\section{Introdução}

A Gestalt-terapia é uma das muitas teorias que compõem o grupo que se compreende como Psicologia Humanista. Retomando os escritos seminais do que viria a ser futuramente intitulado "Psicologia Humanista" nos anos 1960, chamada comumente de "terceira força da Psicologia", Maslow (1962, p.10) afirmam que se tratava de uma "alternativa viável da psicologia objetivista e behaviorista (mecanomórfica) e do freudianismo ortodoxo". Isto significava um modelo teórico-prático que avançasse na compreensão da relação terapêutica estabelecida entre paciente/cliente-terapeuta, que considerasse fortemente suas subjetividades e entendesse o ser humano como potente para a autorrealização, movimento que seria fundamental para sua saúde.
Como uma das diversas epistemologias que orientam a prática clínica - seja da Psicologia, da Psiquiatria, da Musicoterapia, da Pedagogia (Gestaltpedagogia) entre outras áreas - a Gestalt-terapia traz em seu escopo teóricofilosófico menções à Psicologia da Gestalt, à Teoria de Campo, à Fenomenologia, à Teoria Organísmica, ao Teatro de Max Reinhardt, à Eurritmia, à Música, às Artes, à Filosofia Oriental entre outros. Inseridos nesta última, mais especificamente, o Zen-budismo e o Taoísmo. Além de uma orientação tanto pautada no Holismo, com o pensamento de Jan Smuts, quanto no existencialismo - a exemplo disso as aproximações às ideias de Kierkegaard, Martin 
Buber entre outros filósofos. Além do Humanismo mencionado anteriormente ${ }^{2}$.

Desde o seu surgimento oficial em 1951 com a publicação do livro "Gestalt Therapy: Excitement and Growth in the Human Personality" com coautoria explícita de Fritz Perls, Paul Goodman e Ralph Hefferline, e implícita de pessoas como sua esposa Laura Perls entre outros pensadores conhecidos como "o grupo dos sete" (Frazão, 2013), a Gestaltterapia se desenvolveu e cresceu em diversos contextos. Entre estes contextos, as terras brasileiras.

No contexto brasileiro, é comum que a formação se dê pelo menos de duas maneiras: a partir de supervisão com referencial gestaltterapêutico, oferecida geralmente por algum(a) gestalt-terapeuta mais experiente; e/ou com a participação de discentes em cursos de formação/aprimoramento/especialização em Gestalt-terapia. A maioria dos cursos oferecidos parece apresentar formação voltada para a clínica, mesmo que seja reconhecido o referencial gestalt-terapêutico em outras áreas de atuação da Psicologia como organizações (Alvim, 2000), hospitais (Freitas, Stroiek \& Botin, 2010), varas de justiça (Pereira, 2013), na educação (Burow \& Scherpp, 1985; Lilienthal, 1997) entre outros.

É comum ouvir em círculos gestaltterapêuticos que Gestalt-terapia é um jeito de ser, uma arte, ou mesmo uma filosofia de vida. Assim, é possível questionar: Como ocorre a formação de Gestalt-terapeutas? Essa foi uma das perguntas disparadoras para o início deste trabalho que aqui expomos. Como primeiros passos na direção de responder a este questionamento, propusemo-nos a realizar uma revisão narrativa da literatura. De acordo com Rother (2007), esta metodologia de trabalho

2 Uma discussão mais aprofundada sobre a integração dessas diversas teorias, bem como seus principais expoentes, pode ser encontrada em Holanda (2005) e Ribeiro (2011). busca "descrever e discutir o desenvolvimento ou o "estado da arte" de um determinado assunto, sob o ponto de vista teórico ou contextual (...)" incluindo além do levantamento de materiais, uma "análise crítica do autor". Esta modalidade de revisão de literatura, portanto, é não-sistemática, estando as fontes consultadas e utilizadas na construção teórica do trabalho disponíveis ao longo do texto.

$\mathrm{Na}$ busca por mais literatura bibliográfica específica utilizamos tanto materiais já conhecidos por nós quanto a busca em bases de dados consagradas na pesquisa acadêmica brasileira: banco de dissertações e teses e periódicos CAPES. Utilizamos os buscadores nos títulos: "formação de gestaltterapeutas" [0 resultados], "formação" conjugado com o termo "gestalt" [0 resultados], "gestalt therapy training" [um resultado apenas, Kelly \& Howie (2011)], "gestalt-terapeuta" [0 resultados]. Confirmando a escassez de materiais na especificidade desta pesquisa: a formação de Gestalt-terapeutas.

O presente artigo, então, está estruturado da seguinte maneira: um tópico sobre a Gestaltterapia e a sua (des)institucionalização no qual damos o fundo e o contorno para a discussão central deste artigo acercada formação de Gestalt-terapeutas; reflexões acerca da formação fora do Brasil e em terras brasileiras; e, por fim, algumas considerações acerca da temática geral.

\section{Gestalt-terapia e (des)institucionalização}

É comum que citemos o surgimento da Gestalt-terapia basicamente atrelado a: 1) a imagem/figura de Frederick/Fritz Perls; e 2) como uma abordagem psicoterapêutica. $\mathrm{O}$ que não é dito quando a apresentamos desta forma é que a Gestalt-terapia surgiu pelas mãos e ideais de muitas outras pessoas, direta e indiretamente, entre eles Laura Perls e Paul Goodman, bem como o grupo dos sete já mencionados. Isto possui uma implicação direta no objeto que 
discutimos neste artigo: a formação de Gestaltterapeutas.

Nos Estados Unidos, houve uma cisão entre os grupos dos ditos "caras pálidas" e "peles vermelhas". De um lado, Fritz Perls com uma Gestalt-terapia da experiência, da monodramatização, dos workshops curtos e com foco na sua aplicação em situações curtas. Do outro lado, Laura Perls com o Instituto de Gestalt-terapia de Nova Iorque (fundado em 1952), com seu doutorado em Psicologia da Gestalt, com maior rigor acadêmico, na tentativa de institucionalizar e aprofundar teoricamente a Gestalt-terapia. E, entre ambos, Paul Goodman pensando a Gestalt-terapia mais próxima de um movimento político de contestação social com sua ênfase na anarquia e nos movimentos de contracultura. A título de informação, no prefácio da obra "Gestalt-terapia", From \& Miller (1951/1997) discutem longamente as diferenças entre esses modelos surgidos nos EUA.

Um dos impactos disto foi o surgimento de múltiplas Gestalt-terapias. Antes de ser um problema, isto possibilitou que diversos estilos próprios pudessem ser vividos e expressados no fazer psicoterapêutico de orientação gestaltterapêutica. Nas belíssimas palavras de Laura Perls (1992): existirão tantas Gestalt-terapias quanto Gestalt-terapeutas (tradução livre).

Juliano (1992), ao falar sobre a construção histórica da Gestalt-terapia, discorre sobre três modelos diferentes. Para ela, haveria uma "gestalt de cabeça" (grupo de Nova Iorque), uma "gestalt visceral" (Fritz Perls e o trabalho mais experiencial) e uma "gestalt do coração" (Gestalt-terapeutas da primeira geração como o casal Polster e Joseph Zinker).

Ainda sobre esta multiplicidade, Holanda (2005) ao discutir uma Epistemologia da Gestalt-terapia afirma compreender o modelo gestalt-terapêutico em quatro enfoques diferentes: 1) Gestalt-analítica; 2) Gestalt- pragmática; 3) Gestalt-fenomenológica; e 4) Gestalt-existencial. Apesar da sua tentativa de compreensão destes submodelos, o autor afirma que "qualquer expressão que procure resumir a diversidade gestáltica será, invariavelmente, um reducionismo, e caminhará na direção contrária de inúmeras das propostas da mesma abordagem" (p.37). Ao propor isso, o autor não busca cindir a Gestalt-terapia, mas refletir sobre sua heterogeneidade e sua complexidade.

Estas subcategorizações, apesar de questionáveis, são importantes para afirmamos seguramente: sim, existem formas diferentes de compreender, vivenciar e praticar o que é chamado genericamente de "Gestalt-terapia". Saltando a partir desta afirmação, é possível propor, por conseguinte, que há caminhos diferentes trilhados também na formação de Gestalt-terapeutas. E estas formas diversas espalharam-se por diversos lugares outros além dos EUA.

No mundo inteiro, por onde a Gestaltterapia foi difundida, surgiram grupos interessados em promover seu avanço teóricoprático e sua difusão. Como exemplo disto é possível citar a criação de diversas associações ao redor do globo: Asociación Colombiana de Terapia Gestalt (Colômbia) [Fundada em 2007], Fédération Internationale dês Organismes de Formation en Gestalt (França) [Fundada em 1991], European Association of Gestalt Therapy (Europa) [Fundada em 1985], Asociación Española de Terapia Gestalt (Espanha) [Fundada em 1982], Asociación de psicólogos y terapeutas gestalt para el desarrollo (Espanha) [Fundada em 2010], Asociación Gestáltica de Buenos Aires (Argentina) [Fundada em 1980], Association for the Advancement of Gestalt Therapy (Estados Unidos) [Fundada em 1992] entre outras.

Nessa direção, vale citar também: 1) a criação da Universidad Gestalt no México em 1983, reconhecida por Laura Perls como uma universidade organizada com princípios da 
Gestalt-terapia voltados para a difusão do conhecimento, a qual se mantém ativa oferecendo cursos de graduação e pósgraduação com este enfoque até os dias atuais; 2) a possibilidade de receber um higher diploma especificamente em Gestalt-terapia na Universidade da Irlanda (O'Leary, 2013); e 3) o master in Gestalt therapy na Universidade de La Trobe (Austrália). Isto mostra um esforço global na direção não apenas de fomentar as bases gestalt-terapêuticas, mas também de institucionalizá-la e promover seu avanço dentro de parâmetros científicos. ${ }^{3}$

Voltando às associações, destacamos que no Brasil este ainda é um impasse. Houve uma tentativa, no início dos anos 2000, de buscar constituir uma "Associação Brasileira de Gestalt-terapia" ou "Associação Brasileira da Abordagem Gestáltica", fato que gerou discussões dentro da comunidade gestáltica brasileira. Entre os argumentos favoráveis figuraram: a possível importância política de uma institucionalização da Gestalt-terapia, o cuidado com a formação de profissionais e uma forma de regulamentar a atuação destes. Entre os negativos: o possível enrijecimento de uma proposta psicoterapêutica/existencial que surgiu em contexto anárquico e questionador, e o receio de que houvesse uma retirada de autonomia de institutos gestalt-terapêuticos e Gestalt-terapeutas autônomas/os que ofereciam formação.

Em 2016 a proposta voltou a ser discutida no XV Encontro Nacional de Gestaltterapia e XII Congresso Brasileiro da Abordagem Gestáltica havendo uma assembléia geral em que foi constituída uma diretoria

\footnotetext{
${ }^{3}$ Às leitoras e aos leitores interessadas/os, vale a visita às páginas virtuais institucionais destas universidades. 1) Universiad Gestalt (México) http://ugestalt.edu.mx/; http://www.irishgestaltcentre.com/ma-in-gestaltpsychotherapy/ e http://www.latrobe.edu.au/handbook//2011/postg raduate/health-sciences/coursework/hmgt.htm
}

provisória a fim de regulamentar uma possível "Associação Brasileira de Gestalt-terapia e da Abordagem Gestáltica", porém esta ainda carece de um registro formal com estatuto e regimento interno, documentos exigidos para a fundação de associações no Brasil de acordo com a Lei ${ }^{\circ}$ 6.015/73 (artigos 120 e 121).

Em contrapartida, o Brasil possui institutos de Gestalt-terapia em suas cinco regiões, com maior concentração de Institutos na região Sudeste nos Estados do Rio de Janeiro e São Paulo. Fato que historicamente é justificado pela forma como a Gestalt-terapia veio para o Brasil nos anos 1970 (Juliano, 1992; Ribeiro, 2007; Costa, 2008). Além disso, nos últimos anos diversos foram os esforços para o reconhecimento de cursos de Especialização em Gestalt-terapia oferecidos nestes institutos e em Instituições de Ensino Superior. Além da grande produção brasileira de trabalhos de pósgraduação stricto sensu em nível de mestrado e doutorado como já relatado por Holanda \& Karwowski (2004) e Holanda (2009).

Para além dessas discussões em pontos favoráveis/desfavoráveis, o fato de haver um questionamento acerca da forma como a transmissão da Gestalt-terapia se daria/dá abrenos este campo como uma possibilidade para uma pesquisa que compreenda esta multiplicidade em suas bases: a formação. Mas o que a literatura gestáltica nos oferece acerca da formação de Gestalt-terapeutas? Apresentaremos isto na seção seguinte.

\section{Reflexões sobre a Formação de Gestalt- terapeutas}

Inicialmente Perls (1942/2002) parecia não estar interessado em criar um modelo psicoterapêutico como se compreende hoje. Por exemplo, a última parte de sua obra inicial, Ego, Fome e Agressão, foi intitulada "Terapia da Concentração", na qual sugeria diversos exercícios a fim de possibilitar a ampliação de consciência de forma autônoma por aqueles que 
o lessem, como uma autoterapia. Além disso, a história de vida de Perls mostra permanente o seu desinteresse em questões burocráticas e de organização de grupos, mais focado em suas viagens para difundir a Gestalt-terapia através de seus workshops, como descreve em sua autobiografia (Perls, 1969/1979). Isto talvez justifique o pouco interesse que este autor parece ter dado a uma discussão mais profunda e estruturada acerca da formação de gestaltterapeutas de uma forma institucionalizada.

Contudo, ao fazer uma arqueologia de seus estudos, é possível perceber que existem pequenas centelhas desta discussão. Por exemplo, em sua obra póstuma, A Abordagem Gestáltica e Testemunha Ocular da Terapia, Perls (1973/1988) dedica o capítulo "Quem está ouvindo?" para pensar acerca das/dos gestaltterapeutas: que princípios norteiam o seu fazer clínico, qual a importância de sua autenticidade, o que clientes/pacientes buscam etc. Apesar disto, não discute amplamente a formação deste/a cuidador(a).

Para construir a discussão teórica desta sessão, é preciso dar um passo anterior e pensar a formação da/o psicoterapeuta, não necessariamente restrita a um referencial teórico. No Brasil, por exemplo, a formação acadêmica em Psicologia descrita nas Diretrizes Curriculares Nacionais institui bases fundamentais para que o acadêmico se torne um profissional em Psicologia (Psicóloga/o) ao final de sua graduação, não obrigatoriamente um psicoterapeuta. Assim, a formação como psicoterapeuta passa a ser realizada, geralmente, em espaços fora da universidade.

Discorrer acerca da Psicoterapia é importante, mesmo que compreendamos que uma clínica psicológica se faz para além dessa prática. Pimentel (2012) afirma que "a Psicoterapia é uma das formas que a Psicologia Clínica viabiliza socialmente os conhecimentos cientificamente elaborados, sobretudo concepções de subjetividade, alteridade, mundo, compreensão das relações entre sujeitos, da ciência etc." (p.165). Sendo assim fundamental a discussão acerca de tal práxis.

Quem pode exercer a função de psicoterapeuta no Brasil? Não há uma delimitação clara por parte dos conselhos profissionais. Contudo na Classificação Brasileira de Ocupações (Brasil, 2002), a busca pelo termo "psicoterapeuta" indica dois sinônimos para as categorias: 1) "Médico Psicoterapeuta" (Código 2251-33), sendo esta uma subcategoria para a ocupação de profissionais formados em medicina e 2) "Psicoterapeuta" (Código 2515-10), na qual estão incluídos Psicólogas/os e Psicanalistas. No caso de psicólogas/os, estas/es profissionais estão amparados legalmente pela Resolução 010 de 20 de dezembro de 2000 do Conselho Federal de Psicologia que discorre sobre a prática da psicoterapia.

Ao discorrer sobre a ausência desta regulamentação da formação em psicoterapia, Conte (2012) afirma que "a diversidade que caracteriza a Psicologia e as práticas psicoterápicas deve ser discutida mais além de enquadramentos, títulos, listas e regulamentações" (p.153), sugerindo a importância de mais reflexões nesta direção, para além de disputas políticas ou de mercado.

Quanto à formação de gestalt-terapeutas, Bar-Yoseph et al (2008/2014) indagam:

Qual a formação mínima necessária para alcançar um nível aceitável de competência como um gestaltterapeuta? Como se pode medir isso? Seria a compreensão da teoria, a qualidade da aliança de trabalho na relação dialógica ou os resultados efetivos para o processo terapêutico? (...) Formação, supervisão e terapia pessoal são os três blocos de construção na criação de um 
profissional ético, íntegro, criativo e atencioso (p.149)

Apesar de o foco dos autores citados acima ser mais fortemente aproximado de uma pesquisa quantitativa, muito presente na cultura estadunidense da qual fazem parte, estas perguntas são importantes para nortear reflexões acerca da formação de gestalt-terapeutas.

Em estudo sobre a formação do psicoterapeuta na abordagem gestáltica, Cardella (2002) cita Frazão (s/d) para elucidar os objetivos neste processo: o desenvolvimento da autopercepção, o processo contínuo de autoconhecimento do terapeuta, a habilidade para compreender sua percepção (do terapeuta) e a do cliente, o desenvolvimento de raciocínio clínico e o contato consigo mesmo (p.105).

Ribeiro (1994), ao pensar a especificidade de gestalt-terapeutas, afirma que:

o terapeuta gestáltico não é diferente dos terapeutas de outras abordagens, senão em uma única coisa: não é possível ser gestalt-terapeuta sem uma profunda fé na capacidade humana de autoregular-se, sem uma consciência experienciada de que é sendo pessoa que se torna pessoa e que é alargando as próprias fronteiras que uma Gestalt cada vez mais completa é possível (p.184).

Enquanto Bar-Yoseph (2008/2014) e Cardella (2002) discutem a perspectiva do gestalt-terapeuta a partir do tripé formação, terapia e supervisão, Ribeiro (1994) parece se aproximar mais à perspectiva de uma vivência da Gestalt-terapia como filosofia de vida para estes profissionais. Yontef (1998) segue a direção dos primeiros autores citados:

não há padrões consensuais para o que seja uma boa Gestalt-terapia ou um bom Gestalt-terapeuta. Portanto, está a cargo do interessado em Gestalt-terapia avaliar cuidadosamente a formação educacional, clínica e o treinamento pessoal das pessoas que se denominam Gestalt-terapeutas (p.26-27).

As perspectivas destes diversos autores parecem não se anular, deixando claro o processo formativo e vivencial inerentes à prática da Gestalt-terapia. Vale um destaque também às criticas epistemológicas à Abordagem Gestáltica: apesar da concepção bastante difunda em Gestalt-terapia de que "o terapeuta é seu próprio instrumento" (Polster \& Polster, 2001/1973, p.35), Loffredo (1992, p.152) tece críticas de que esta compreensão em nada difere de outros sistemas teóricos da Psicologia e da Psicanálise, considerando a noção de contratransferência como um ponto deixado de lado pela Gestalt-terapia, mesmo que nesta tenhamos a ênfase nos processos de consciência e seus desdobramentos.

Tal aproximação com a Psicanálise também permanece caso pensemos uma suposta "estrutura de formação" quando comparada à Gestalt-terapia. Em seus escritos, Aguiar (2005) arrisca uma discussão sobre a formação da/o Gestalt-terapeuta infantil pontuando "a importância da teoria" (p.294) bem como da "psicoterapia pessoal e supervisão" (p.296), porém isto parece se aproximar bastante do já conhecido tripé psicanalítico freudiano que compreende a formação da/o Analista pautada em: análise pessoal/estudo teórico/supervisão.

Apesar de não raro lermos que a Gestaltterapia também é um sistema anárquico (Perls, 1992) ou uma noção de contestação política (Rocha, 2005), ainda são raros materiais bibliográficos que mencionem diretamente a importância da formação de Gestalt-terapeutas incluírem questões relacionadas à discussão de gênero, raça e questões de classe, também pilares críticos caso se queira conservar o caráter revolucionário e questionador da Gestaltterapia. 


\section{Cursos de formação em Gestalt-terapia no Brasil e legislação}

Entre fins dos anos 1990 e parte dos anos 2000 houve intensa discussão da Psicologia brasileira para que fossem delimitadas áreas de especialidades para a Psicologia. O resultado dessas discussões, em nível nacional e realizada por diversos conselhos regionais, gerou a Resolução CFP no 013/2007 que "institui a Consolidação das Resoluções relativas ao Título Profissional de Especialista em Psicologia e dispõe sobre normas e procedimentos para seu registro".

Após esse fato, houve um movimento de diversos institutos gestalt-terapêuticos para validar seus cursos de Gestalt-terapia como especializações (pós-graduação lato sensu). Isto trazia credibilidade, além de certificação para as/os profissionais que realizavam o curso nestas instituições. As exigências da Associação Brasileira de Ensino da Psicologia - ABEP - e do Conselho Federal de Psicologia eram extensas, porém alguns institutos conseguiram atender a elas. A antiga lista de cursos credenciados ficava disponível no site do CFP (s/d).

Porém, em 2014 foi protocolada a Ação Civil Pública $\mathrm{n}^{\circ}$ 5994-36.2013.4.01.3800, em trâmite na $20^{\mathrm{a}}$ Vara Federal da Seção Judiciária de Minas Gerais, a partir da qual o Conselho Federal de Psicologia ficou impossibilitado de reconhecer cursos de Institutos Autônomos (como a maioria dos cursos de Gestalt-terapia no Brasil) como especializações, passando essa função a ser realizada exclusivamente por Instituições de Ensino Superior (universidades e faculdades, sejam IES públicas ou IES privadas), como é possível verificar no site do Conselho Federal de Psicologia (CFP, 2014).

$\mathrm{Na}$ nota oficial do Conselho Federal de Psicologia é dito que: "Em atendimento à decisão judicial, o Conselho Federal de Psicologia (CFP) informa que estão suspensos os novos credenciamentos e recredenciamentos de cursos de especialização em Psicologia (CFP, 2014)", informando ainda que havia sido constituído um grupo de trabalho para verificar outras possibilidades legais contra a decisão.

Alguns institutos buscaram então validar seus cursos a partir de chancelas com diversas IES pelo país. Essa prática, apesar de conhecida na área, constitui irregularidade. A legislação do Ministério da Educação acerca dos cursos de pós-graduação institui que:

Os cursos de especialização somente podem ser oferecidos por instituições de ensino superior já credenciadas que poderão oferecer cursos de especialização na área em que possui competência, experiência e capacidade instalada. A instituição credenciada deve ser diretamente responsável pelo curso (projeto pedagógico, corpo docente, metodologia etc.), não podendo se limitar a "chancelar" ou "validar" os certificados emitidos por terceiros nem delegar essa atribuição a outra entidade (escritórios, cursinhos, organizações diversas). Não existe possibilidade de "terceirização" da sua responsabilidade e competência acadêmica. (...) (Brasil, 2007, grifos nossos)

Após essa decisão alguns dos institutos e centros de Gestalt-terapia brasileiros passaram a ofertar os seus cursos como cursos livres de Formação em Gestalt-terapia, com o mesmo corpo docente, buscando sustentar a mesma qualidade técnica e praticamente o mesmo contorno curricular, porém sem ao final oferecer um certificado de especialista. Não é objetivo deste trabalho avaliar ganhos e perdas nesse processo, mas pontuamos este fato por considerá-lo um tocante no que diz respeito ao tema da formação brasileira. 
Os cursos de formação em Gestaltterapia no Brasil costumam ter duração entre um ano (modalidade semanal) e três anos (modalidade mensal) sendo constituídos, de forma geral, por aulas teóricas, estágio clínico supervisionado (supervisão) e a participação de suas/seus discentes em workshops de imersão gestáltica (vivências). E possuem como públicoalvo: profissionais e estudantes das áreas de Psicologia e Psiquiatria. Em alguns casos é possível encontrar cursos voltados para a população em geral, porém sem um enfoque clínico psicoterapêutico.

Vale um destaque também acerca da pós-graduação stricto sensu: mestrados e doutorados. No Brasil, não temos nenhum Programa de Pós-Graduação em Gestalt-terapia (stricto sensu) como em outros países. Porém, há docentes vinculadas/os a diversos programas que se colocam disponíveis para orientar Gestalt-terapeutas e pessoas interessadas na área. A concentração desses programas costuma ser nas áreas da Psicologia e/ou da Educação.

Ainda quanto a questões de legislação, não raro é encontrar Psicólogas/os recémformadas/os que se autointitulam Gestaltterapeutas seja por terem tido contato com a Gestalt-terapia em cursos de graduação, por terem participado de um evento acadêmico e identificar-se com os pressupostos da abordagem ou mesmo por ter concluído curso de Formação Básica em Gestalt-terapia ou algum curso online. Isto não acontece somente com a orientação gestalt-terapêutica, mas também com outras abordagens psicológicas. De toda forma, esta é uma questão vindoura para a Associação Brasileira de Gestalt-terapia e da Abordagem Gestáltica caso tenha como meta pensar a Formação de Gestalt-terapeutas no Brasil.

Em sua totalidade, os trabalhos referidos nesta análise focam-se em questões ligadas à clínica privada no modelo tradicional de psicoterapia individual. Isso é um reflexo da Gestalt-terapia, parecendo ainda estar concentrada nessa área de atuação. Isto elucida pouco o que seria fundamental em uma formação em Gestalt-terapia caso consideremos sua atuação fora do modelo clínico.

\section{Considerações finais}

Ainda há pouco material bibliográfico específico acerca da formação de Gestaltterapeutas. Isto parece ocorrer por pelo menos dois motivos: a incipiente pesquisa em Gestaltterapia no Brasil e ainda necessidade de refletirmos acerca da nossa formação. Quais qualidades queremos que Gestalt-terapeutas brasileiras/os desenvolvam em nossas formações?

Como circunscrever um "currículo mínimo" para ensinar uma prática que é ao mesmo tempo vivência e teoria? $\mathrm{O}$ advento de uma Associação Brasileira de Gestalt-terapia \& da Abordagem Gestáltica nos auxilia nessa direção ou nos "enrijece"? Bar-Yoseph, Philippson, O’Neil e Brownell (2008/2014) já afirmaram que: 1) as formações variam de acordo com os países e culturas nas quais estão inseridas (p.134); e 2) a formação de Gestaltterapeutas exige uma "pedagogia vivencial", sendo a/o formador(a) um guia nesse processo (p.132).

De certo é possível afirmar que formar Gestalt-terapeutas é uma tarefa difícil e complexa por exigir de quaisquer pessoas envolvidas nesse processo a habilidade de sintetizar temas complexos entendendo a multiplicidade das teorias que compõem a Gestalt-terapia e considerando-a como heterogênea. Colocar tais questões acerca dos diversos modelos e formas singulares da atuação gestalt-terapêutica abre a reflexão para buscarmos o que é comum à abordagem. Seria o seu suposto caráter fenomenológico? Sua postura existencial? A forma como entrelaça e alinhava suas diversas teorias? Este artigo traz questionamentos para que novas reflexões sigam nessa direção e fertilizem ainda mais o 
crescimento da Gestalt-terapia em nossas terras tupiniquins.

\section{Referências}

Aguiar, L. (2005). Gestalt-terapia com crianças: teoria e prática. Campinas: Livro Pleno.

Alvim, M. B. (2000). Ensaio Para um Modelo Psicológico de Análise Organizacional na Perspectiva da Abordagem Gestáltica. (Dissertação de Mestrado em Psicologia). Brasília: Universidade de Brasília.

Brasil. (2002) Classificação Brasileira de Ocupações. Recuperado em: http://www.mtecbo.gov.br/cbosite/pages/saib aMais.jsf. Visita em 28 de fevereiro de 2014.

Brasil. (2007). Resolução no 1 de 8 de Junho de 2007. Estabelece normas para o funcionamento de cursos de pós graduação lato sensu, em nível de especialização. Ministério da Educação. Recuperado em: http://portal.mec.gov.br/cne/arquivos/pdf/rce s001_07.pdf.

Bar-Yoseph, T. L., Philippson, P., O’Neil, B., \& Brownell, P. (2014) Formação de terapeutas. In: Philip Brownell (Org.). Manual de teoria, pesquisa e prática em Gestalt-terapia. (pp. 131-151). (Original publicado em 2008).

Burow, O. A., \& Scherpp, K. (1985). Gestaltpedagogia: um caminho para a escola e a educação. São Paulo: Ed. Summus.

Cardella, B. H. P. (2002). A Construção do Psicoterapeuta - uma abordagem gestáltica. São Paulo: Ed. Summus.

Conte, B. S. (2012). Psicoterapia: O percurso histórico nos desafios por uma formação sem regulamentação. In: Adriano Holanda (Org.). O campo das psicoterapias: reflexões atuais (pp.144-154). Curitiba: Juruá.

Conselho Federal de Psicologia (2007). Resolução no 013/2007. Recuperado em: https://site.cfp.org.br/wpcontent/uploads/2007/09/resolucao2007_13.p $\underline{\mathrm{df}}$

Conselho Federal de Psicologia (s/d). Título de especialista. Recuperado em: http://site.cfp.org.br/servicos/titulo-deespecialista/cursos-credenciados/

Conselho Federal de Psicologia (2014).

Credenciamento de cursos de especialista em

Psicologia. 02 de julho de 2014. Recuperado em:

http://site.cfp.org.br/credenciamento-erecredenciamento-de-cursos-de-especialistaem-psicologia-estao-suspensos/

Costa, D. S. M. (2008). História da Gestalt-

terapia no Brasil contada por seus

"Primeiros Atores": Um estudo

historiográfico no eixo São Paulo-Brasília.

2008. (Dissertação de Mestrado em

Psicologia). Universidade Católica de Goiás, Goiânia.

Frazão, L. (2013). Um pouco de história... Um pouco dos bastidores. In: Frazão, L. M. \& Fukumitsu, K. O. (Orgs.). Gestalt-terapia: Fundamentos epistemológicos e influências filosóficas. São Paulo: Ed. Summus.

Freitas, J. L., Stroiek, N. N., \& Botin, D. (2010). Gestalt-terapia e o diálogo psicológico no hospital: uma reflexão. Revista da Abordagem Gestáltica, 16(2), 141-147.

From, I., \& Miller, M. V. (1997). Introdução à edição do The Gestalt Journal. In: Perls, F.; Hefferline, R.; Goodman, P. (Org.). Gestaltterapia. (pp.15-29). São Paulo: Ed. Summus. (Original publicado em 1951).

Holanda, A. F., \& Karwowski, S. L. (2004). Produção acadêmica em Gestalt-terapia no Brasil: análise de mestrados e doutorados. Psicologia: Ciência e Profissão, 24(2), 6071.

Holanda, A. F. (2009). Gestalt-terapia e abordagem gestáltica no Brasil: análise de mestrados e doutorados (1982-2008). Estudos e Pesquisas em Psicologia, 9(1), 98123.

Holanda, A. F. (2005). Elementos de epistemologia da Gestalt-terapia. In: Adriano Furtado Holanda \& Nilton Julio de Faria (Orgs). Gestalt-terapia e contemporaneidade: contribuições para uma construção epistemológica da teoria e da 
prática gestáltica (pp. 21-53), Campinas: Livro Pleno.

Juliano, J. C. (1992). Gestalt-Terapia: revisitando as nossas estórias. Revista de Gestalt, II, no 2, (pp. 7- 21).

Kelly, T., \& Howie, L. (2011). Exploring the influence of gestalt therapy training on psychiatric nursing practice: Stories from the field. International Journal of mental health nursing. V (20). doi: 10.1111/j.14470349.2010.00729.x

Lei ${ }^{\circ} 6.015$ de 31 de dezembro de 1973. (1973). Dispõe sobre os registros públicos e de outras previdências. Casa civil.

Recuperado em: http://www.planalto.gov.br/ccivil_03/leis/L6 015original.htm

Lilienthal, L. A. (1997). A Gestaltpedagogia Sai às Ruas Para Trabalhar com Crianças e Educadores de Rua. (Dissertação de Mestrado em Psicologia). Universidade de São Paulo, São Paulo.

Loffredo, A. M. (1992). De Cotovelos Apoiados no Para-Peito da Palavra: Do Cenário Clínico, Qual é o Horizonte? (Tese de Doutorado em Psicologia). Universidade de São Paulo, São Paulo.

Maslow, A. H. (1962). Introdução à Psicologia do Ser. Trad. de Álvaro Cabral. Rio de Janeiro: Eldorado.

O'Leary, E. (2013). Gestalt therapy around the world. New York: Wiley-Blackwell.

Pereira, C. V. (2013). Psicologia Jurídica e Abordagem Gestáltica: Um Encontro nas Varas de Família: Curitiba: Juruá.

Perls, F. (1979). Escarafunchando Fritz: dentro e fora da lata de lixo. São Paulo: Ed. Summus. (Original publicado em 1969).

Perls, F. (2002). Ego, fome e agressão. São Paulo: Ed. Summus. (Original publicado em 1942).

Perls, F. (1988). A abordagem Gestáltica e testemunha ocular da terapia (2a ed.). Rio de Janeiro: LTC (Original publicado em 1973).

Perls, F. S., Hefferline, R., \& Goodman, P. (1951). Gestalt therapy: Excitement and
Growth in the Human Personality. New York: Julian Press.

Perls, L. (1994). Viviendo en los Límites. Valencia: Promolibro.

Pimentel, A. (2012). Psicoterapia e clínica ampliada: Diferenciando horizontes interventivos. In: Adriano Holanda (Org.). $O$ campo das psicoterapias: reflexões atuais (pp.165-178). Curitiba: Juruá.

Polster, E., \& Polster, M. (2001). Gestaltterapia integrada. São Paulo: Ed. Summus (Obra original publicada em 1973).

Ribeiro, J. P. (1994). Gestalt Terapia: $O$ processo Grupal. Uma visão fenomenológica, da Teoria do Campo e Holística. São Paulo: Ed. Summus.

Ribeiro, J. P. (2011). Conceito de mundo e pessoa em Gestalt-terapia. São Paulo: Ed. Summus.

Rocha, S. L. C. O. (2005). Gestalt e relações de gênero: a emergência de novas

masculinidades e feminilidades nos modos de ser homem e ser mulher hoje. In: Frazão, L. M. \& Rocha, S.L.C.O.; (Org.). Gestalt e Gênero: configurações do masculino e feminino na contemporaneidade. Campinas: Livro Pleno.

Ribeiro, W. F. R. (2007). Gestalt-Terapia no Brasil: recontando a nossa história. Revista da Abordagem Gestáltica, 13(2), 255-259.

Rother, E. T. (2007). Revisão sistemática x revisão narrativa. Editorial. Acta Paul Enferm. 20(2).

Yontef, G. M. (1998) (2). Processo, diálogo e awareness: ensaios em Gestalt-terapia. São Paulo: Ed. Summus.

Dados sobre os autores:

- Lázaro Castro Silva Nascimento é Psicólogo Gestalt-terapeuta (CRP-08/20085). Doutorando no Programa de Pós-Graduação em Psicologia Clínica e Cultura da Universidade de Brasília. Coordenador do Instituto Figura-Fundo - 
Processos formativos em Gestalt-terapia (Curitiba/PR).

- Jorge Ponciano Ribeiro é PhD. Gestaltterapeuta. Professor Emérito da Universidade de Brasília. Fundador e presidente do Instituto de Gestalt-terapia de Brasília (IGTB).

PSI UNISC, Santa Cruz do Sul, Vol. 1, n. 1, jul./dez. 2017, p.<153-153>. 